\title{
Effect of the Volume Fraction of Jute Fiber on the Interlaminar Shear Stress and Tensile Behavior Characteristics of Hybrid Glass/Jute Fiber Reinforced Polymer Composite Bar for Concrete Structures
}

\author{
Chan-Gi Park \\ Department of Rural Construction Engineering, Kongju National University, Yesan 32439, Republic of Korea \\ Correspondence should be addressed to Chan-Gi Park; cgpark@kongju.ac.kr \\ Received 5 March 2016; Revised 1 June 2016; Accepted 7 June 2016 \\ Academic Editor: Marta Fernández-García \\ Copyright (C) 2016 Chan-Gi Park. This is an open access article distributed under the Creative Commons Attribution License, which \\ permits unrestricted use, distribution, and reproduction in any medium, provided the original work is properly cited. \\ Hybrid glass/jute fiber reinforced polymer (HGJFRP) composite bars were manufactured for concrete structures, and their \\ interlaminar shear stress and tensile performance were evaluated. HGJFRP composite bars were manufactured using a combination \\ of pultrusion and braiding processes. Jute fiber was surface-treated with a silane coupling agent. The mixing ratio of the fiber to the \\ vinyl ester used in the HGJFRP composite bars was $7: 3$. Jute fiber was used to replace glass fiber in proportions of $0,30,50,70$, \\ and $100 \%$. The interlaminar shear stress decreased as the proportion of jute fiber increased. Fractures appeared due to delamination \\ between the surface-treated component and the main part of the HGJFRP composite bar. Tensile load-strain curves with $50 \%$ jute \\ fiber exhibited linear behavior. With a jute fiber volume fraction of $70 \%$, some plastic deformation occurred. A jute fiber mixing \\ ratio of $100 \%$ resulted in a display of linear elastic brittle behavior from the fiber; however, when the surface of the fiber was coated \\ with poly(vinyl acetate), following failure, the jute fiber exhibited partial load resistance. The tensile strength decreased as the jute \\ fiber content increased; however, the tensile strength did not vary linearly with jute fiber content.
}

\section{Introduction}

The importance of developing new, environmentally friendly materials has increased since the recognition of global warming. Much has been investigated in research and development of biocomposite materials, especially the development of materials that can replace conventional, petroleumbased organic materials with naturally abundant, inexpensive, lightweight natural fibers [1-5]. Depending on their intended applications, composite biomaterials have been fabricated with biodegradable polymeric resins without reinforcing fibers or with natural fibers and the polymeric resin matrix used in existing glass fiber composites [3]. Generally, the commercial thermoplastic or thermosetting resins used widely in existing glass fiber composites are used as the polymeric resin matrix in natural fiber composites [1-3]. This allows one to use the same processing and molding methods as used with existing polymeric composites. Several researchers have shown that the properties and performance of biocomposite materials made with natural fibers are as good as those of conventional glass fiber composites, such that the former might replace the latter [3]. Composite polymeric reinforcements are widely used in structural concrete [6-9]. To reduce the problems associated with the corrosion of iron reinforcing bars, research has examined various applications of fiber reinforced polymer (FRP) composite bars manufactured with a combination of glass, carbon, and aramid fibers in a polymeric matrix [10-16]. These FRP composites do not corrode iron bars and possess excellent long-term durability [6-8]. They are, however, expensive and often cost-prohibitive. This study describes the development and characterization of a biocomposite reinforcing material for use in concrete structures [10,11]. This new composite may be used as a replacement for glass fiber reinforced polymer (GFRP) composites. The price of natural fibers is roughly $1 / 3$ to $1 / 5$ that of glass fibers, making most natural 
TABLE 1: Mechanical properties of fiber and matrix resin.

\begin{tabular}{lcccc}
\hline Mechanical properties & $\begin{array}{c}\text { Vinyl ester } \\
\text { resin }\end{array}$ & E-glass & $\begin{array}{c}\text { Jute } \\
\text { fiber }\end{array}$ & PVA fiber \\
\hline Tensile stress $(\mathrm{MPa})$ & 86 & 3,400 & 393 & 510 \\
Elastic modulus $(\mathrm{GPa})$ & 3.17 & 71 & 55 & 61 \\
Fiber density $\left(\mathrm{g} / \mathrm{cm}^{3}\right)$ & - & 2.62 & 1.3 & 1.26 \\
\hline
\end{tabular}

fiber-based composites significantly less expensive. However, natural fibers are significantly less dense $\left(1.2 \sim 1.5 \mathrm{~g} / \mathrm{cm}^{3}\right)$ than glass fibers $\left(2.56 \mathrm{~g} / \mathrm{cm}^{3}\right)[3,5]$. As a result, the strength and elasticity of natural fibers are also lower than those of glass fibers. However, the specific strength and specific elasticity, which are based on the density of the two systems, are equivalent $[3,5]$. This means that biocomposites prepared with the same density as that of glass fiber composites can match the elasticity and strength of the latter. In addition, given the same volume of material, the biocomposite will be lighter and less expensive than the glass fiber composite $[3,5]$. Consequently, compared with conventional GFRP composites, those based on natural fibers boast advantages in terms of economics and weight. However, because the physical and dynamic properties of natural fiber-based composites are generally less desirable than those of glass fiber composites, it is difficult to create suitable composite reinforcing materials using $100 \%$ natural fiber. Consequently, this study examined ways to reduce the amount of glass fiber used in GFRP reinforcing materials by replacing it with natural fibers. Hybrid glass/jute fiber reinforced polymer (HGJFRP) composite bars were fabricated with both glass and jute fibers. The relative proportions of jute and glass fibers were varied systematically to gauge their effect on the performance of the resulting concrete reinforcing material.

\section{Experimental Program}

2.1. Materials. This study evaluated the tensile characteristics and interlaminar shear stress of HGJFRP composite bars for use as concrete reinforcements. A vinyl ester resin was used as the polymeric matrix. Epoxy, vinyl ester, and polyester resins are widely used as polymeric matrices. Polyester resins are unsuitable because they are easily damaged by $\mathrm{OH}$ ions [6]; this is also true of vinyl ester resins. The use of esterfree alternatives can greatly reduce this shortcoming [6]. The vinyl ester resin used here (Hetron ${ }^{\mathrm{TM}}$ epoxy vinyl ester resin, Ashland Performance Materials, USA) is highly durable and affordable. Table 1 lists the properties of the E-glass fiber, jute fiber, PVA fiber, and vinyl ester resin.

2.2. Manufacturing of the HGJFRP Composite Bars. A silane coupling agent was used to strengthen the interfacial binding between the jute fibers and vinyl ester resin. Silane binders were used, and the method for surface treatment was determined using the results of previous research to provide good binding between the jute fiber and the resin [17-20]. $\gamma$-Methacryloxypropyltrimethoxysilane (MPS; Shinetsu Silicone Co., Ltd., Korea) was used as the coupling agent and was hydrolyzed for $1 \mathrm{~h}$ after dilution with a cosolvent of methanol
TABLE 2: Mixture ratio of HGJFRP composite bar.

\begin{tabular}{lccc}
\hline \multirow{2}{*}{ Mix number } & \multicolumn{2}{c}{ Fiber (vol.\%) } & Vinyl ester (vol.\%) \\
& Jute fiber & Glass fiber & \\
\hline Number 1 & $0(0 \%)^{*}$ & 70 & 30 \\
Number 2 & $21(30 \%)$ & 49 & 30 \\
Number 3 & $35(50 \%)$ & 35 & 30 \\
Number 4 & $49(70 \%)$ & 21 & 30 \\
Number 5 & $70(100 \%)$ & 0 & 30 \\
\hline
\end{tabular}

${ }^{*}$ Jute fiber substitution rate.

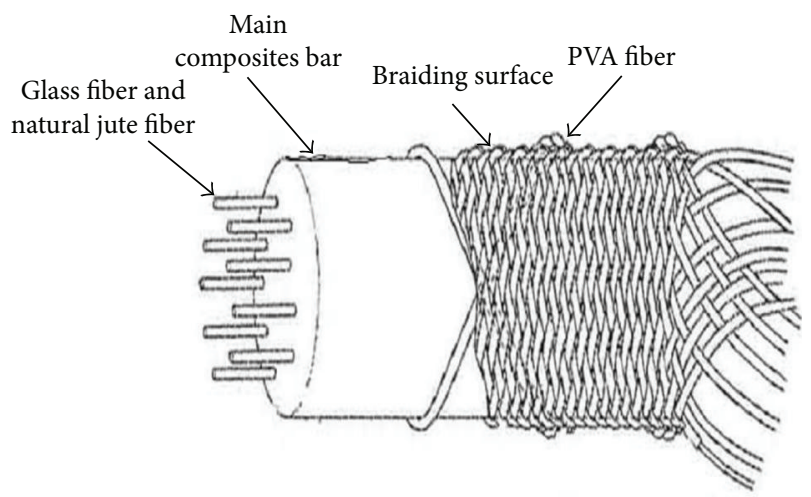

FIGURE 1: Braiding surface of HGJFRP composite bars in this study.

and distilled water (mass ratio $95: 5$ ). The $\mathrm{pH}$ of the solution was adjusted to 4.0 using acetic acid. At this time, the concentration of the silane coupling agent was fixed at $0.8 \mathrm{wt} \%$. Jute fiber was then soaked in this hydrolyzed solution for 30 minutes. The fibers were then removed from the solution, dried in an oven at $110^{\circ} \mathrm{C}$, and allowed to dry completely at room temperature. Five different kinds of HGJFRP composite bars were prepared with various volumetric ratios of jute fiber, glass fiber, and vinyl ester resin (Table 2). A combination of extrusion molding and braiding processes were used to manufacture the sample specimens. An extrusion molding process was used to prepare the internal core of the composite bars, while a braiding process was used to alter their surface shape. The core of the reinforcing bar was formed using jute fibers that were treated with a silane coupling agent and mixed with the glass fibers in the vinyl ester resin. Ribs were formed on the surface of the bar, and a PVA fiber-braiding process was carried out, as shown in Figure 1. This surface treatment was used to prevent separation of the core of the bar and the surface region. The HGJFRP composite bars were then cured. Figure 2 shows photographs of different stages during the fabrication process.

2.3. Interlaminar Shear Stress Test. While the surface of the HGJFRP composite bars was treated using a braiding process, the core of the bars was manufactured using a pultrusion process. Due to the one-directional alignment of both the jute and glass fibers, this process may result in the destruction of the fiber/matrix interface. The interfacial bonding is strong along the longitudinal direction of the fibers and weak across the diameter of the fibers. Therefore, efforts were made to 


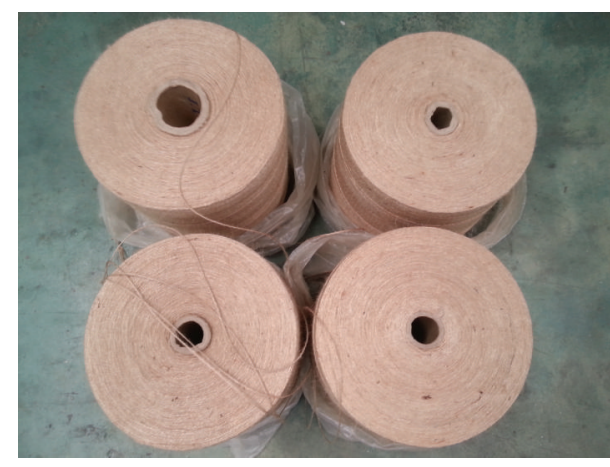

(a)

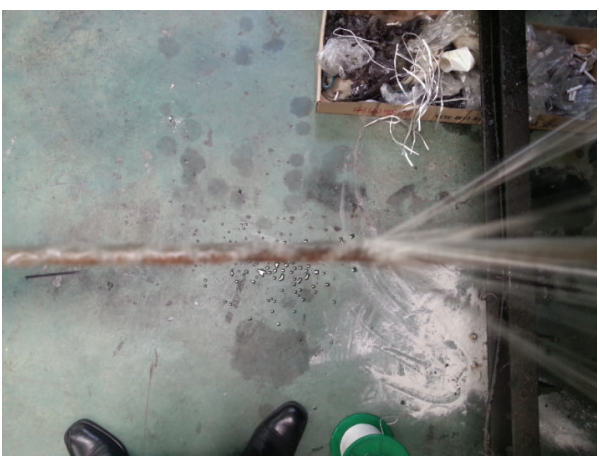

(c)

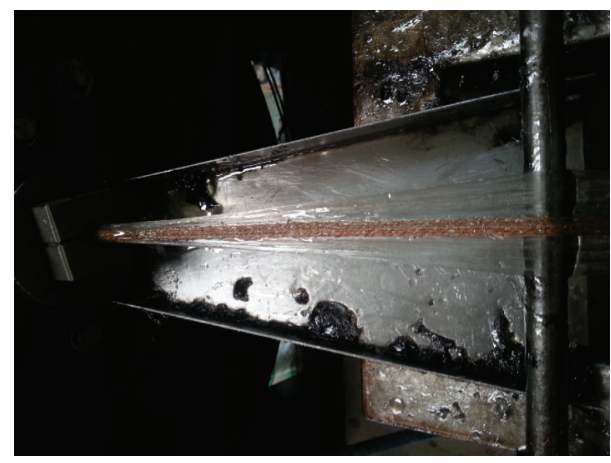

(b)

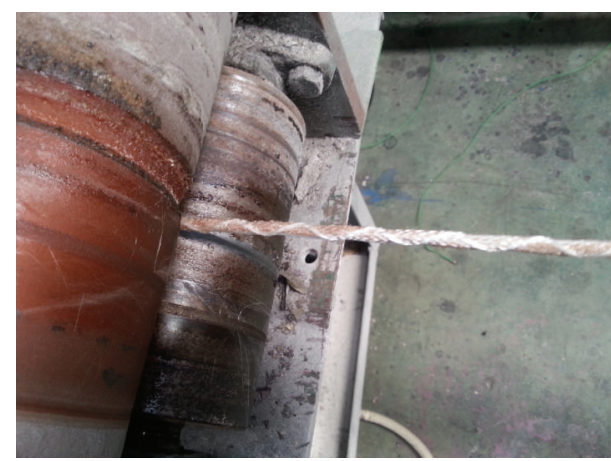

(d)

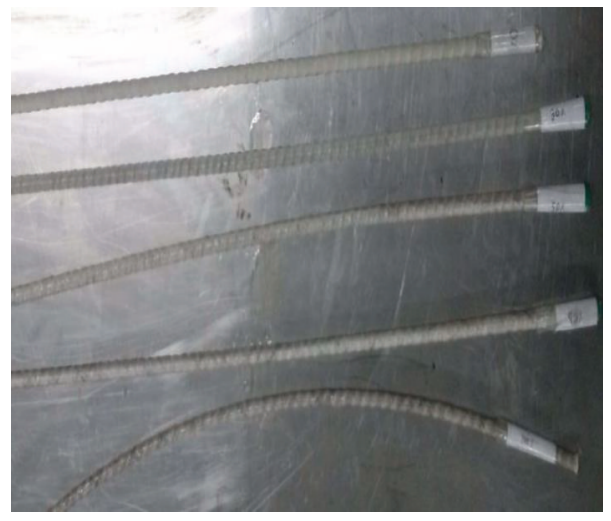

(e)

FIGURE 2: Manufacturing of HGJFRP composite bar. (a) Jute fiber. (b) Impregnation. (c) Braiding. (d) Pultrusion. (e) Geometry of HGJFRP composite bar.

not only improve the adherence of the fibers to the concrete through the braiding process but also increase the strength of the composite bar in the direction of bending. Shot beam tests in accordance with ASTM D 4475 were performed to gauge the interlaminar shear stress at the interface between the fibers and matrix in the bending direction of the composite bar.

The interlaminar shear stress $(\mathrm{MPa})$ of the HGJFRP composite bars was calculated as follows [10]:

$$
S=0.849 \frac{P}{D^{2}}
$$

where $P$ is the fracture load $(\mathrm{N})$ and $D$ is the diameter of HGJFRP composite bars $(D=50 \mathrm{~mm})$. Figure 3 shows the apparatus used for the shot beam tests.

2.4. Tensile Tests. Tensile tests on the composite bars were performed in accordance with ACK 440K. In FRP tensile tests, it is difficult to consistently fix the FRP composite bar in the test apparatus. It is also difficult to measure tensile strength precisely because failure often results from slippage between the specimen grip and the FRP composite bar. To try to eliminate this, the center of the grip point was reinforced 


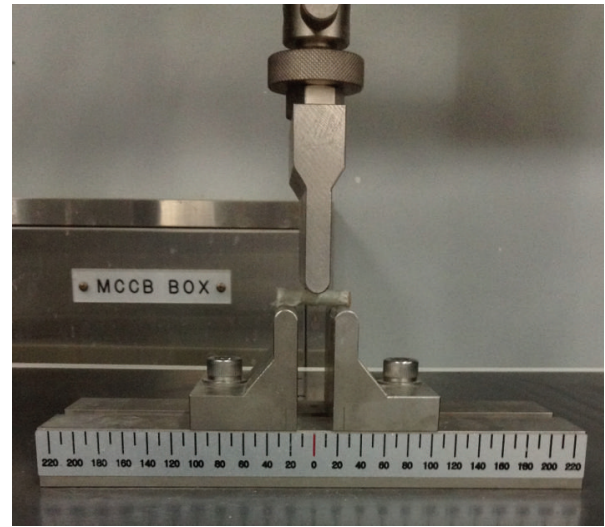

FIgURE 3: Shot beam test setup.

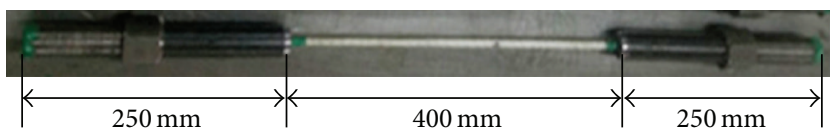

FIGURE 4: Geometry of tensile test grip and test specimens.

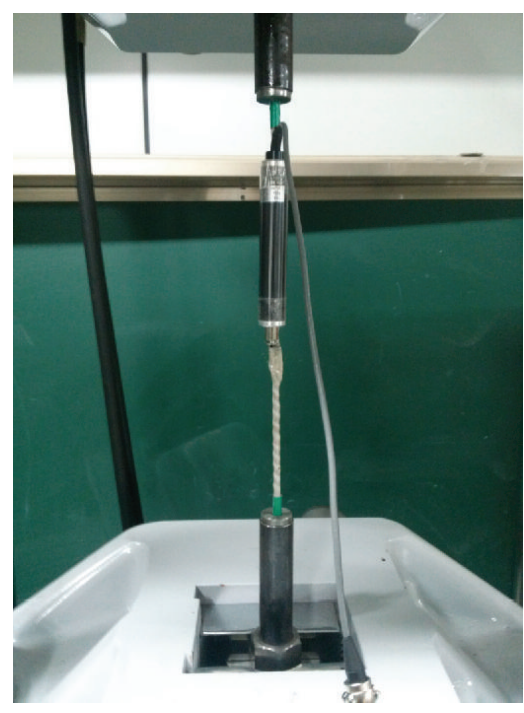

Figure 5: Tensile test setup.

with silica mixed with epoxy. This prevented slippage at the anchorage point by increasing the surface friction between the grip and composite bar. Figure 4 shows the shapes of the specimens used in tensile tests, and Figure 5 shows the tensile test apparatus. The grip was $250 \mathrm{~mm}$ long and $30 \mathrm{~mm}$ in diameter, and the diameter of HGJFRP composite bars was $5 \mathrm{~mm}$. The length of HGJFRP composite bars was $1000 \mathrm{~mm}$, and the length excluding the grips was $500 \mathrm{~mm}$. Tensile tests were carried out using an adjustable universal tensile machine (UTM) with a capacity of $1,000 \mathrm{kN}$, and the strain rate was $5 \mathrm{~mm} / \mathrm{min}$. The strain on the CFRP reinforcement bar was measured using an LVDT.

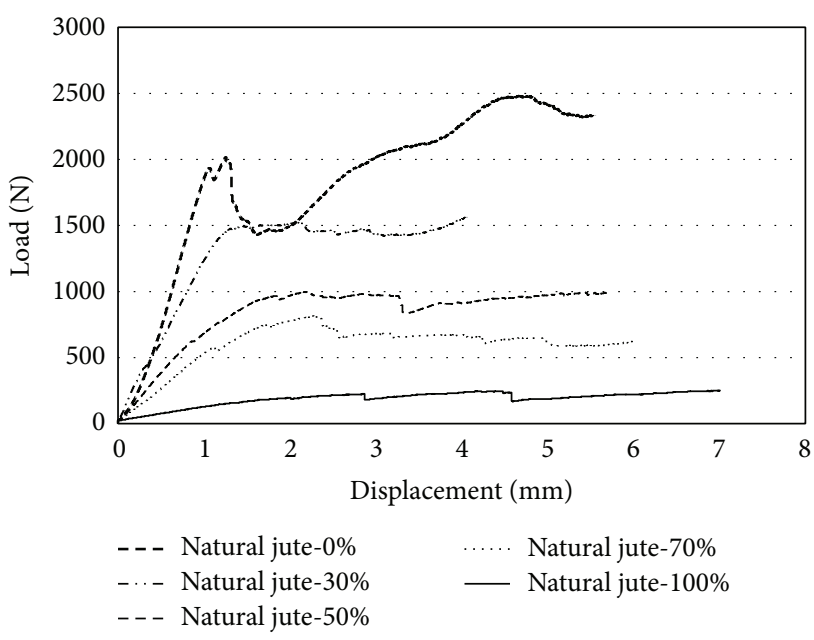

FIGURE 6: Interlaminar shear load-displacement behavior of HGJFRP composite bar.

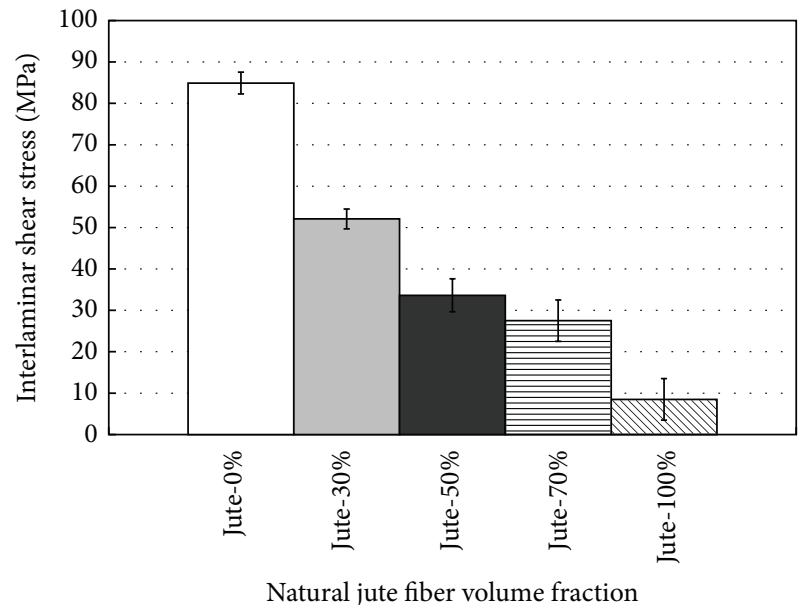

Figure 7: Interlaminar shear stress of HGJFRP composite bar.

\section{Results and Discussion}

3.1. Interlaminar Shear Behavior. Figure 6 shows loaddisplacement curves of the HGJFRP composite bars. Initially, as the fraction of jute fiber increased, the increase in displacement exceeded that of the load. These results show that although the same load was imposed, the displacement increased, indicating a decrease in overall stiffness. These initial load-displacement curves were maintained up to a proportion of $30 \%$ jute fiber. As the proportion increased to 50,70 , and $100 \%$, the change in displacement exceeded that of the load, indicating that the interface between the vinyl ester resin and jute or glass fibers was not sufficiently strong to prevent separation. Therefore, the fibers split while receiving the load and became bent. As the proportion of jute fiber increased, the interface weakened.

3.2. Interlaminar Shear Stress. Figure 7 shows that interlaminar shear stress decreased as the fraction of jute fiber increased. Figure 8 shows a test specimen following failure 


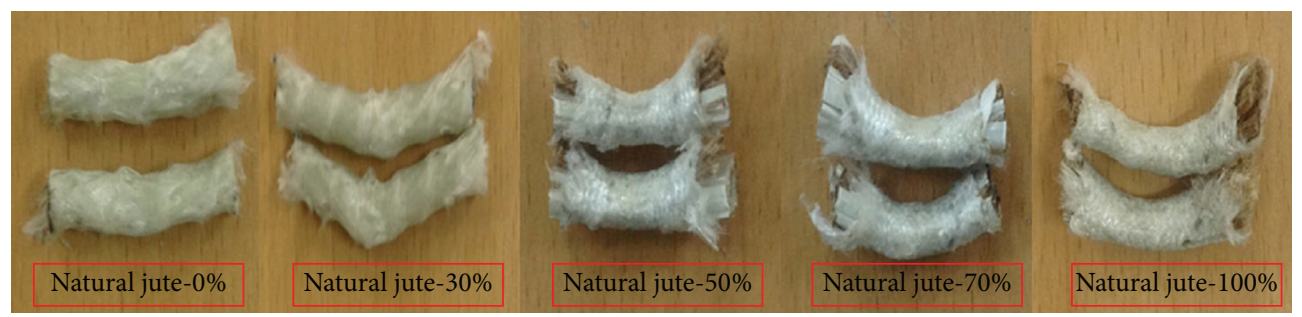

FIGURE 8: Fracture deformation of HGJFRP composite bar after shot beam tests.

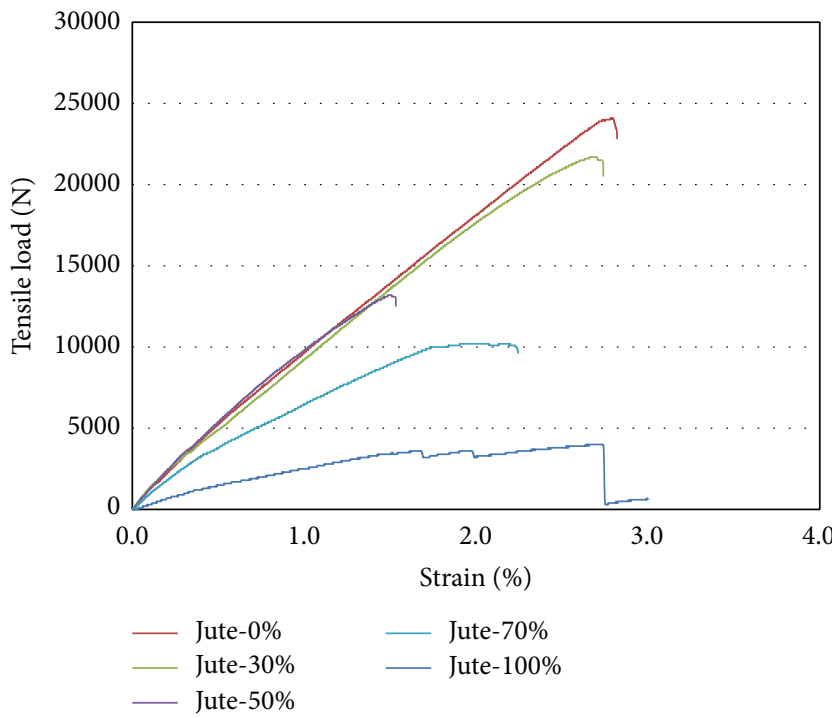

Figure 9: Tensile load-displacement behavior of HGJFRP composite bar.

during a short beam test. Failure appears to be the result of interfacial separation between the surface and internal core of the HGJFRP composite bar. This became more apparent as the proportion of jute fiber increased. With a jute fiber fraction in the range $0-30 \%$, failure occurred with little interfacial separation between the surface and core components. The separation phenomenon was more evident with mixing ratios of $50-100 \%$, in which separation between the core jute and glass fibers increased, along with separation of the jute fibers themselves. The braiding process used on the jute fiber surface was effective and prevented splitting due to interfacial separation of the fibers.

3.3. Tensile Behavior. Generally, FRP composite reinforcing materials are brittle and exhibit linear elastic behavior. The tensile load-displacement curve shown in Figure 9 indicates similar behavior with our HGJFRP composite bars. The HGJFRP composite bar with a jute fiber mixing ratio of $0 \%$ was a GFRP composite bar, which exhibited brittle and linear behavior. In this work, glass fiber and jute fiber reinforcements were used. A comparison between the dynamic properties of glass fiber and those of jute fiber revealed that the elastic constant of the glass fiber was $71 \mathrm{GPa}$ and that of the jute fiber was $55 \mathrm{GPa}$ (i.e., the elastic constant of the glass fiber was $29 \%$ greater than that of the jute fiber). The tensile strength of the glass fiber was $3400 \mathrm{MPa}$, and the strain was $4.79 \%$; the tensile strength of the jute fiber was $393 \mathrm{MPa}$, and the strain was $0.72 \%$. The tensile strength of the glass fiber was 8.65 times higher than that of the jute fiber, and the deformation of the glass fiber was 6.75 times greater than that of the jute fiber. Thus, the jute fiber failed prior to the glass fiber. The density of jute fiber was approximately half that of glass fiber; thus, for a given mass, the volume and number of fibers will be approximately twice that of glass fiber. For this reason, the tensile load prior to failure was larger for FRP composite bars with the same cross-sectional area. If the volume fraction of high-elastic-modulus glass fiber is greater than the volume fraction of the low-elastic-modulus jute fiber, then the composite will become brittle. This is because, following failure of the glass fiber, the jute fiber also fails. In addition, with a glass fiber content of $30 \%$, because the mixing ratio of jute fiber was high, plastic deformation occurred following failure of the glass fibers. This is due to the fact that, with a relatively low mixing ratio of glass fiber, following failure of the glass fiber, plastic deformation occurs until the jute fiber (partially) fails. With only jute fiber, although linear elastic brittle behavior was observed, partial resistance of the load was observed, without failure of fibers where the surface was treated with PVA fiber. Because of the low strength of the jute fiber, we observed the following. First, the core of the HGJFRP composite bars failed, and then the displacement continued to increase while the PVA fiber provided resistance. Then the load decreased during failure of the PVA fibers. In other words, following failure of the HGJFRP composite bars, although the PVA fiber exhibited some resistance, linear elastic behavior was observed due to the behavior of the PVA fiber.

3.4. Elastic Modulus and Tensile Strength. Figure 10 shows the measured elastic constant of the HGJFRP composite bars. The elastic modulus decreased as the mixing ratio of jute fiber increased. With jute fiber mixing ratios of $0 \%, 30 \%$, and $50 \%$, the elastic modulus was $42.86 \mathrm{GPa}, 42.31 \mathrm{GPa}$, and $41.98 \mathrm{GPa}$, respectively (i.e., the elastic modulus did not vary significantly). However, with mixing ratios of $70 \%$ and $100 \%$, the elastic modulus decreased markedly to $25 \mathrm{GPa}$ and $7.14 \mathrm{GPa}$, respectively. As shown in Figure 11, the tensile strength decreased as the proportion of jute fiber increased. The tensile strength was $1229,1105,667,509$, and $203 \mathrm{MPa}$ for jute fiber 


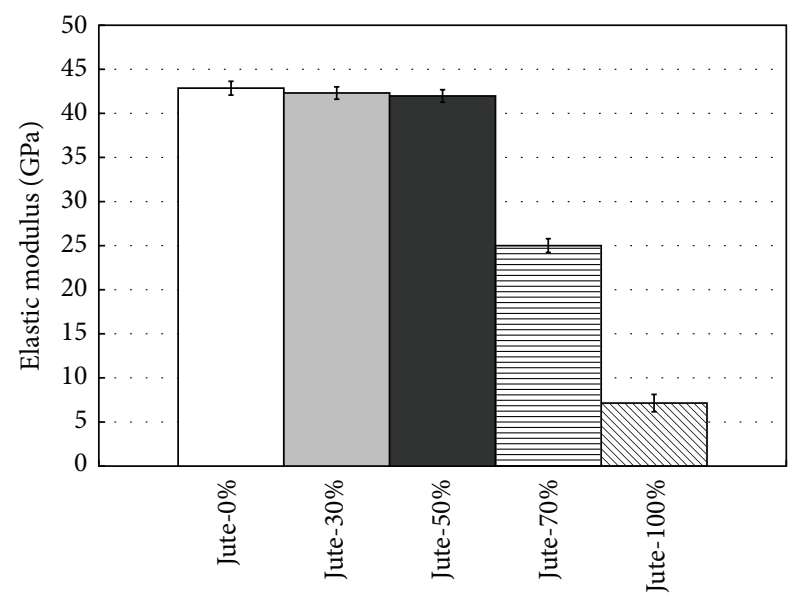

Natural jute fiber volume fraction

Figure 10: Elastic modulus.

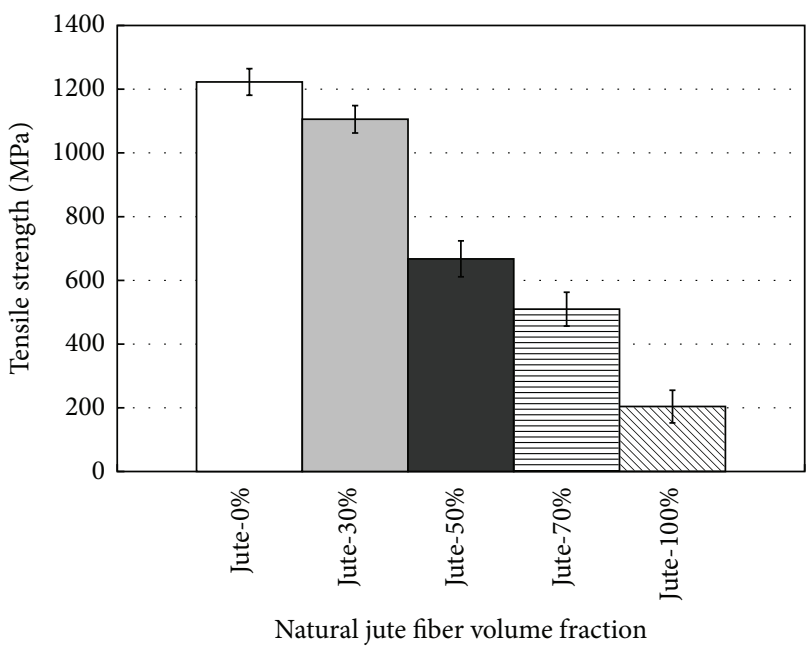

FIGURE 11: Tensile strength of HGJFRP composite bar.

mixing ratios of $0,30,50,70$, and $100 \%$, respectively. The tensile strength decreased by approximately $50 \%$ as the proportion of jute fiber increased from zero to $50 \%$. This indicates that the overall strength of the composite decreased as the jute fiber content increased, as the tensile strength of glass fiber is greater than that of jute fiber. Previous research into hybrid FRP bars, with two or more different fibers, revealed that the tensile strength of the hybrid FRP bars decreased as the fraction of fibers with low elastic constants and low strength increased. We found that the tensile strength decreased as the jute fiber content increased. The tensile strength of the glass fiber was approximately 8.65 times greater than that of the jute fiber. Thus, we may expect that the tensile strength of the HGJFRP composite bars will decrease significantly as the mixing ratio of jute fiber increases. As the mixing ratio of jute fiber increased to $30 \%, 50 \%, 70 \%$, and $100 \%$, the tensile strength was observed to decrease to $89.9 \%, 54.3 \%, 41.4 \%$, and $16.5 \%$ of that with only glass fiber, respectively. The tensile strength did not decrease linearly with the mixing ratio of jute fiber. For the HGJFRP composite bar with a 50:50 mix of glass fiber and jute fiber, the tensile strength was approximately $23.12 \%$ (i.e., 1/4.325) of that of the bar mixed with glass fiber only. This is because, with all of the other variables held constant, the tensile strength of the HGJFRP composite bars with only glass fiber should be 8.65 times that of HGJFRP composite bars with only jute fiber, as the tensile strength of glass fiber was 8.65 times greater than that of jute fiber.

3.5. Tensile Failure Surface. Figure 12 shows a HGJFRP composite bar following tensile testing. The braiding process was applied during manufacture of the HGJFRP composite bar. Glass fiber and jute fiber were supplied simultaneously during manufacture of the HGJFRP composite bars, after which the braiding process was applied to coat the bars with PVA fiber, with the aim of improving the bond to concrete. Failure of the HGJFRP composite bars began with separation from the surface-treated part of the HGJFRP composite bars, particularly with low jute fiber content. Because the tensile strength of the HGJFRP composite bars increased as the fraction of glass fiber increased, the surface-treated part separated prior to failure of the HGJFRP composite bar. Thus, with no jute fiber, it was observed that failure occurred simultaneously with surface separation (Figure 12(a)). With 30\% jute fiber, the jute fiber failed, and the surface-treated part separated and failed prior to failure of the glass fiber (Figure 12(b)). With $50 \%$ jute fiber, the jute fiber failed almost simultaneously with the glass fiber, along with separation of the surface-treated region (Figure 12(c)). With 70\% jute fiber, failure of the jute fiber and glass fiber occurred almost simultaneously, along with separation of the surface-treated region (Figure 12(d)). With $100 \%$ jute fiber, failure of the main HGJFRP composite bar was observed prior to failure of the surface-treated part, and the PVA fiber remained partially intact, exhibiting some resistance against the load (Figure 12(e)). The form of the samples following failure revealed that, with high jute fiber content, the main HGJFRP composite failed, and, with small jute fiber content, failure occurred due to the separation of the surface from the main HGJFRP composite bar.

\section{Conclusions and Recommendation}

HGJFRP composite bars were manufactured with systematically varied volume fractions of jute fiber and investigated for use in concrete reinforcement. The effects on the interlaminar shear stress and tensile strength of these composites were studied and can be summarized as follows.

(1) The interlaminar shear load-displacement behaviors of composites containing 0-30\% jute fiber were similar. For jute fiber contents of $\geq 50 \%$, the increase in displacement exceeded that of the load, indicating a decrease in stiffness.

(2) The interlaminar shear stress decreased as the volume fraction of jute fiber increased. It appears that failure during these tests resulted from interfacial separation between the silane-treated surface and jute fiber core bar. This was more apparent as the volume fraction of jute fiber increased. 


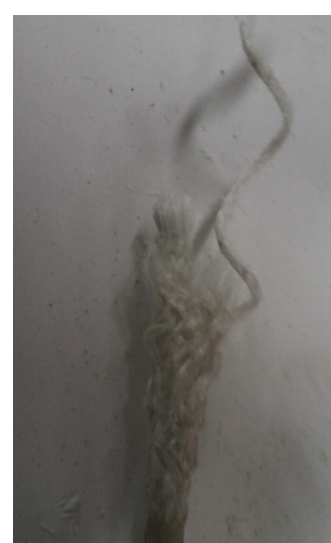

(a)

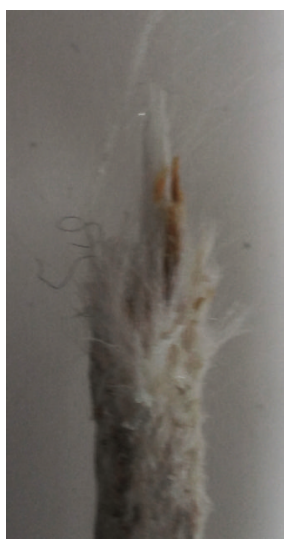

(b)

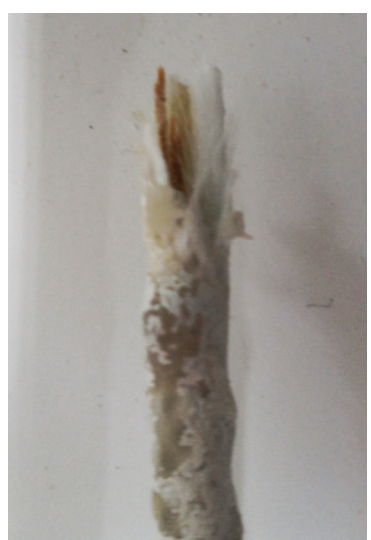

(c)

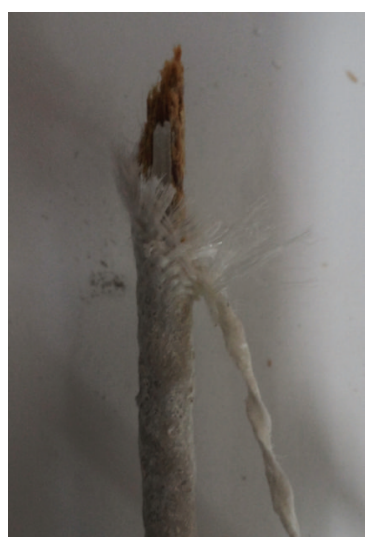

(d)

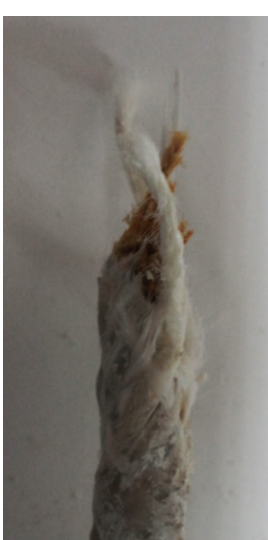

(e)

FIGURE 12: Fracture deformation of HGJFRP composite bar after tensile strength tests. (a) Jute fiber (0\%). (b) Jute fiber (30\%). (c) Jute fiber (50\%). (d) Jute fiber (70\%). (e) Jute fiber (100\%).

(3) With $70 \%$ jute fiber, the behavior of glass fiber was observed until failure. After failure, due to the presence of the jute fibers, linear elastic behavior was initially observed, followed by plastic deformation. Because of the large elastic constant, the high tensile strength, and the low strain rate that was applied, the plastic deformation region was small. Furthermore, with $100 \%$ jute fiber, linear elastic behavior was observed.

(4) The tensile strength of the HGJFRP composite bars decreased as the jute fiber volume fraction increased. This is because the tensile strength of jute fiber is approximately $1 / 8.65$ that of the glass fiber.

(5) Following tensile failure, for high jute fiber volume fractions, the main HGJFRP composite bars failed. With low jute fiber volume fractions, failure occurred due to separation of the surface from the core HGJFRP composite bars at the location of the PVA coating.

(6) The purpose of this study was to evaluate the possibility of replacing GFRP composite bar with HGJFRP composite bar for concrete reinforcement. The test results showed that the interlaminar shear stress and tensile strength of HGJFRP composite bars were lower than those of GFRP composite bars and decreased as the volume fraction of jute fiber increased. However, the tensile strength of the GFRP composite bars was approximately 3-4 times greater than the steel bar. Therefore, the HGJFRP composite bars have potential as a replacement for steel rebar for applications in concrete reinforcement.

(7) As part of future work, we plan to improve the performance of HGJFRP composite bars by investigating surface treatment methods and changes to the type of polymer resin used.

(8) For applications in concrete reinforcement, further work is required to compare the performance of HGJFRP composite bars with that of steel rebar.

\section{Competing Interests}

The author declares that there is no conflict of interests regarding the publication of this paper.

\section{Acknowledgments}

This research was supported by the Basic Science Research Program through the National Research Foundation of Korea (NRF) founded by the Ministry of Education (NRF2013R1A1A4A01011776).

\section{References}

[1] V. Mishra and S. Biswas, "Physical and mechanical properties of bi-directional jute fiber epoxy composites," Procedia Engineering, vol. 51, pp. 561-566, 2013.

[2] D. Ray, B. K. Sarkar, S. Das, and A. K. Rana, "Dynamic mechanical and thermal analysis of vinylester-resin-matrix composites reinforced with untreated and alkali-treated jute fibres," Composites Science and Technology, vol. 62, no. 7-8, pp. 911-917, 2002.

[3] I. M. De Rosa, C. Santulli, F. Sarasini, and M. Valente, "Postimpact damage characterization of hybrid configurations of jute/glass polyester laminates using acoustic emission and IR thermography," Composites Science and Technology, vol. 69, no. 7-8, pp. 1142-1150, 2009.

[4] R. Codispoti, D. V. Oliveira, R. S. Olivito, P. B. Lourenço, and R. Fangueiro, "Mechanical performance of natural fiberreinforced composites for the strengthening of masonry," Composites Part B: Engineering, vol. 77, pp. 74-83, 2015.

[5] A. N. Shah and S. C. Lakkad, "Mechanical properties of jutereinforced plastics," Fibre Science and Technology, vol. 15, no. 1, pp. 41-46, 1981.

[6] J.-P. Won, S.-J. Lee, Y.-J. Kim, C.-I. Jang, and S.-W. Lee, "The effect of exposure to alkaline solution and water on the strength-porosity relationship of GFRP rebar," Composites Part B: Engineering, vol. 39, no. 5, pp. 764-772, 2008.

[7] J. W. Chin, T. Nguyen, and K. Aouadi, "Effects of environmental exposure on Fiber-Reinforced Plastic (FRP) materials used in 
construction," Journal of Composites Technology and Research, vol. 19, no. 4, pp. 205-213, 1997.

[8] P. K. Dutta and D. Hui, "Low-temperature and freeze-thaw durability of thick composites," Composites Part B: Engineering, vol. 27, no. 3-4, pp. 371-378, 1996.

[9] F. R. Jones, J. W. Rock, and A. R. Wheatley, "Stress corrosion cracking and its implications for the long-term durability of Eglass fibre composites," Composites, vol. 14, no. 3, pp. 262-269, 1983.

[10] C. G. Park, J. P. Won, and J. K. Yoo, "Long-term effect of chemical environments on FRP reinforcing bar for concrete reinforcement," Journal of the Korea Concrete Institute, vol. 15, no. 6, pp. 811-819, 2003.

[11] ACI 440H, Guide for the Design and Construction of Concrete Reinforced with FRP Bars, American Concrete Institute Committee 440, 2000.

[12] X. Lin and Y. X. Zhang, "Evaluation of bond stress-slip models for FRP reinforcing bars in concrete," Composite Structures, vol. 107, no. 1, pp. 131-141, 2014.

[13] R. J. Gravina and S. T. Smith, "Flexural behaviour of indeterminate concrete beams reinforced with FRP bars," Engineering Structures, vol. 30, no. 9, pp. 2370-2380, 2008.

[14] J.-P. Won and C.-G. Park, "Effect of environmental exposure on the mechanical and bonding properties of hybrid FRP reinforcing bars for concrete structures," Journal of Composite Materials, vol. 40, no. 12, pp. 1063-1076, 2006.

[15] J. F. Davalos, Y. Chen, and I. Ray, "Effect of FRP bar degradation on interface bond with high strength concrete," Cement and Concrete Composites, vol. 30, no. 8, pp. 722-730, 2008.

[16] H. A. Rasheed, R. Nayal, and H. Melhem, "Response prediction of concrete beams reinforced with FRP bars," Composite Structures, vol. 65, no. 2, pp. 193-204, 2004.

[17] S. J. Park, J. S. Jin, and P. K. Park, "Improvement of interfacial bonding of glass fiber/unsaturated polyester composites using silane coupling agent: effects of silance concentration," Textile Science and Engineering, vol. 37, no. 6, pp. 324-328, 2000.

[18] H. W. Lee, "Glass fiber reinforced plastic pole," Korea patient, No.1020030038036, 2003.

[19] Kumoh National Institute of Technology Industry-Academic Cooperation Foundation, "A method for preparing natural fiber/polycardanol biocomposities," Korea Patient, No. 1010458880000, 2008.

[20] Jeil Industries Co Ltd, "Natural fiber reinforced polylactic acid resin composition," Korea Patient, no. 1008954930000, 2009. 

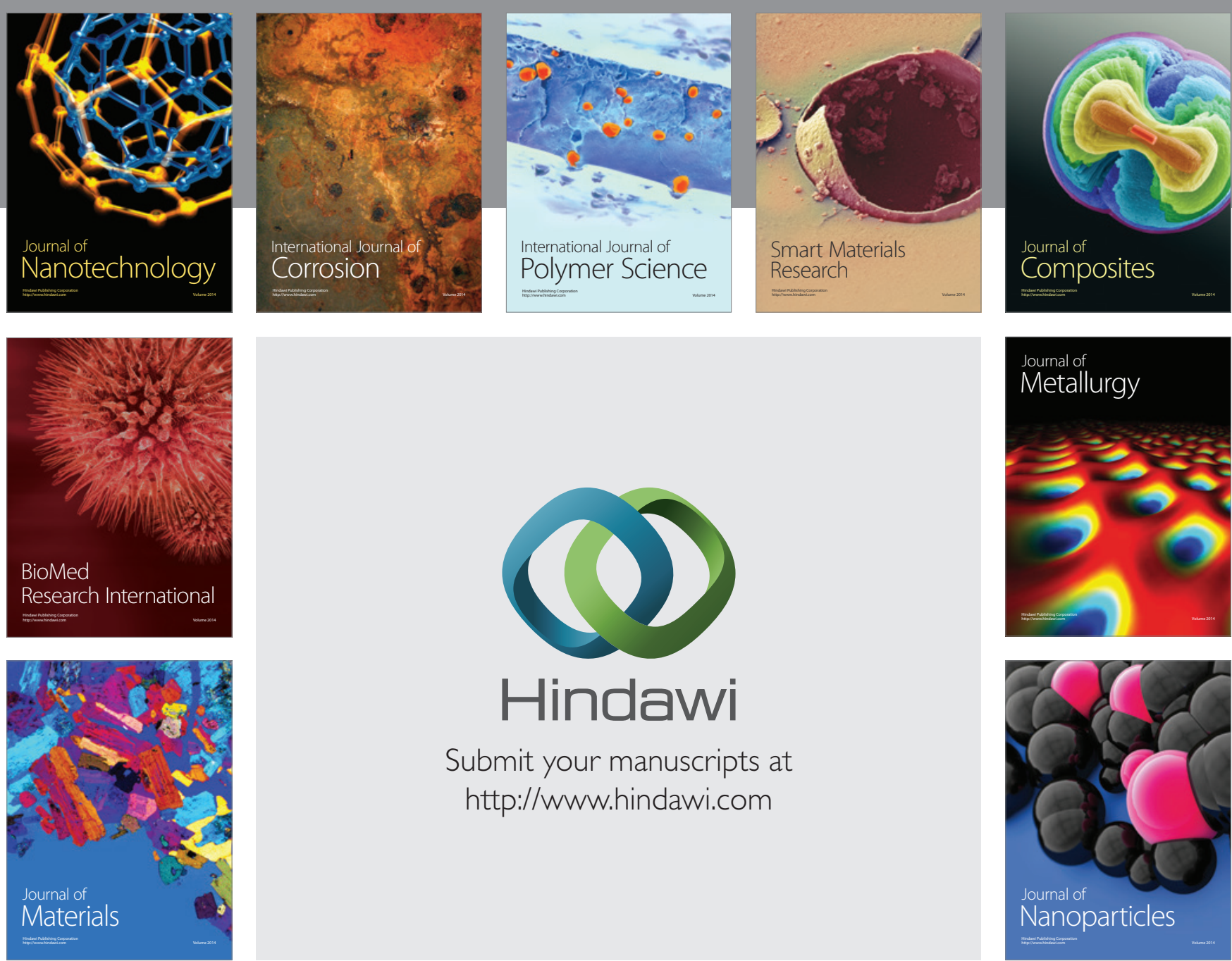

\section{Hindawi}

Submit your manuscripts at

http://www.hindawi.com

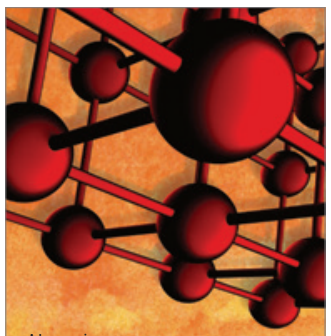

Materials Science and Engineering
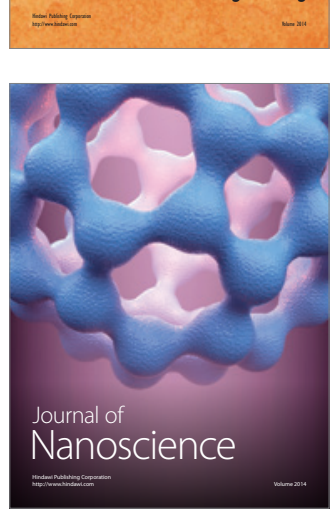
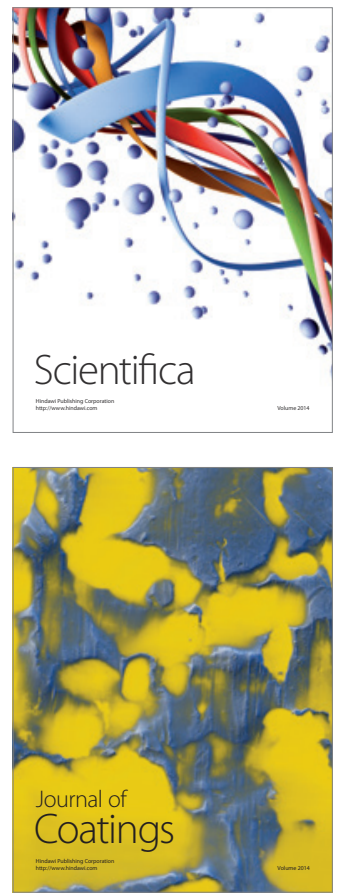
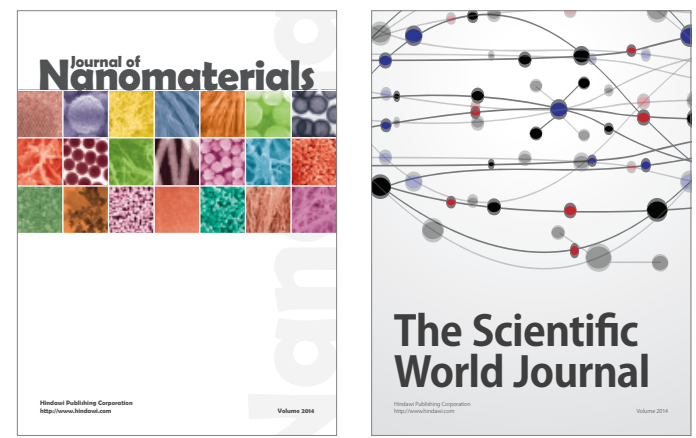

The Scientific World Journal
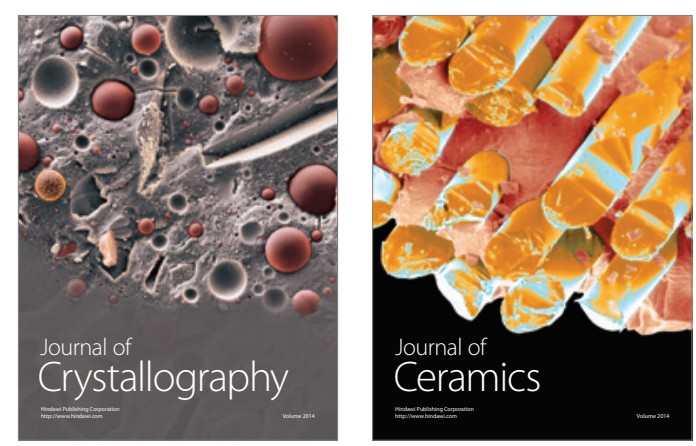
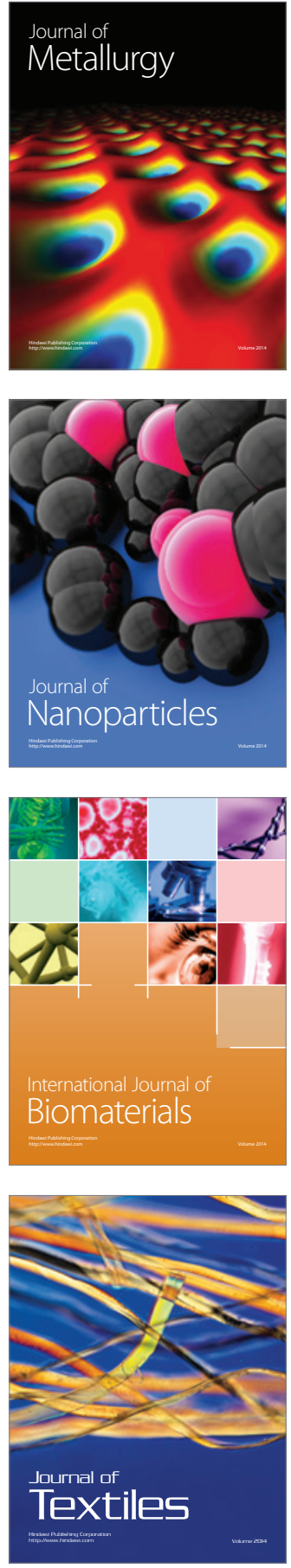